\title{
Schematic Structure and Linguistic Realizations of Virtual English Language Lectures in the Social Context of the Pandemic Covid-19
}

\author{
$1^{\text {st }}$ Amrin Saragih ${ }^{1}, 2^{\text {nd }}$ Khairunnisa br Batubara ${ }^{2}, 3^{\text {rd }}$ Yuni Khairina $^{3}$ \\ \{amrinsaragih@unimed.ac.id ${ }^{1}$, khaibara@unimed.ac.id ${ }^{2}$, yuni.khairina@unimed.ac.id ${ }^{3}$ \}
}

Universitas Negeri Medan, Indonesia ${ }^{1,2,3}$

\begin{abstract}
English language lectures are held virtually at the English Language Department, Faculty of Languages and Arts, Universitas Negeri Medan due to the containment of the pandemic covid-19 spread. The virtual lectures as the social context potentially affects the text of classroom interaction. Specifically, the social context affects the schematic structures and their linguistic realizations. This study is intended to analyze the virtual lectures in order to study its schematic structures and their linguistic realizations. The design of the study is a descriptive qualitative one. The data sources of are virtual English language lectures held by lecturers. The lectures are related to Integrated English language skills (listening, speaking, reading and writing), Structure, Vocabulary, and Pronunciation. The data are utterances of the lecturers and the students which are obtained by applying (participant) observation, interview and document analysis. Linguistic analysis is based on theories of systemic functional linguistics (SFL). The findings of the study indicates that the schematic structures of the virtual lectures and and their linguistic realizations are affected by the social context. Findings of the study results in both theoretical and practical implications and are expected to be applied in developing and evaluating virtual English language and in assessing the student achievements resulted from the virtual lectures.
\end{abstract}

Keywords: Schematic Structure, Linguistic Realization, Covid 19, Pandemic.

\section{Introduction}

Schematic or generic structure refers to the orders of communicative or rhetorical functions in a text [1] [2]. Language learning or teaching activities form a text [3], which is constituted by schematic structures. There have been studies on (schematic) structure of language teaching or learning activities in the classroom, such as [4] with their teacher and student talk model, Sinclair and Coulthard (1975) with their IRF model, [5] with teacher talk, [6] with lecture model, [7] with phasal elements in lectures and [8] with her curriculum genre. All of the studies were conducted in the conventional classrooms or with reference to the contexts of classroom situations where the teachers or lecturers were physically close or in face to face interactions. In different manner, the present study is conducted in or with reference to the online or virtual classes where teachers or lecturers are physically distant from the students or learners. The physical distance between the participants in such virtual classroom may be thousands of kilometers. The present study finds out that virtual mode [9] of interaction affect schematic stuctures of the English language lectures and consequently 
linguistic realizations of the schematic or generic structures. The new finding in the present study highlights that virtual or online English language lectures are differently structured from the conventional or traditional ones. In addition, linguistic realizations of the schematic structures are different from those of the traditional or conventional ones. This paper addresses three main points, namely the schematic or generic structure of the virtual English language lectures, their linguistic realizations, and the reasons for existence of the schematic structures and their linguistic realizations.

\section{Method}

This study applied a descriptive qualitative design was conducted to virtual English language lectures held by the lecturers of the English Language Study Program, Faculty of Languages and Arts, Universitas Negeri Medan in May 2021. Thus, the sources of the data were virtual English language lectures. The data were utterances of the lecturers and students in the virtual classes. The classes involved in this study are ones related to the usage and use of English language, they are 1) Integrated English language skills (listening, speaking, reading and writing), 2) Structure, 3) Vocabulary, and 4) Pronunciation.

Each title of the four lectures is represented by three sessions, which were recorded and transcribed into written forms. Ideally there will be twelve transcribed English language sessions of lectures as the sources of the data. However, the study is still in progress and at this stage only four lectures were used as the data sources. This means that the finding displayed in the present paper is still tentative as the rest of eight lectures will be further analysed. The data were collected by applying three instruments, namely (participant) observation, interview and document or text analysis. Utteranes of the lecturers and students were analysed in order to determine linguistic realizations. The analysis of the lecture texts and linguistic categories used are based on systemic functional linguistics (SFL) as developed by [10]. Thus, where metafunctional categories such as Process, Participants, Circumstance, Statement, Questions, Offer, Commant, Mood, Paratactic, Hypotactic relations are used to describe or categorize lexicogrammatical features.

\section{Results and Discussion}

\subsection{Schematic Structures}

A virtual English language lecture forms a text and proceeds in stages. The stages form schematic structures of the text. The schematic strutures of the virtual text with reference to its constituent and proportion.

Constituents. With reference to its constituents or elements, the schematic strutures are constituted by ten elements. In other words, the schematic structure of the virtual lecture consists of

GREETING $\Lambda$ ([\{CLASS CHECKING $\}] \mathrm{n}) \Lambda$ (ORIENTATION) $\Lambda$ [[PRESENTATION $] \mathrm{p} / \mathrm{h}$ $\Lambda$ ([[GROUP WORK $]$ p) $\Lambda$ [[DISCUSSION]]p $\Lambda$ CONSOLIDATION $\Lambda$ EVALUATION $\Lambda$ REFLECTION $\Lambda$ CLOSURE 
where $\Lambda$ means 'followed by', (...) indicates 'optionality', $[\ldots]$ m means 'reiteration', $\{\ldots\}$ indicates 'omnipresence'. The [[...]]p means 'embedding of text paratactically' or 'compound text' and $[[\ldots]] \mathrm{p} / \mathrm{h}$ indicates 'embedding of text paratactically and hypotactically' or 'compound and complex text'. As indicated, the schematic structures are linear in nature.

At the stage of Greeting the lecturer greets the students in the virtual class. Due to the containment of the pandemic Covid-19 spread, the class is held on line or virtually. In addition to the common expressions used, such as Good Morning, Good Afternoon...etc in the conventional classroom, the expressions of blessing such as hope you are well, or stay healthy, etc...follows the greetings. As the class participants may stay in other different time zones the greeting may be doubled as Good Morning to a participant living in one time zone and Good Afternoon to another living behind or ahead of the previous time zone.

The stage of Class Checking is optional, reiterative and omnipresent. The stage is optional in the sense that the stage may and may not occur in a virtual lecture. The stage is reiterative in the sense that the stage potentially occur once, twice, three times, four times, five times...up to $n$ times. The omnipresent feature of the stage indicates that the stage may occur before of after any stage. The activities done by the lecturer at this stage are meant to check or make sure the presence, understanding and awareness or alertness of the students. Firstly, expressions such as are you all in, who has not appeared in the list, where is $P$ ?... are meant to check the presence or absence of the students. This obviously includes apperceptian or readiness of the students to attend the calss. Secondly. the teacher cheks the students' understanding related to the content or issue raised in the lecture. The teacher may raise questions, do you have any question, does it make sense?, is it understood?...etc. Thirdly, the lecturer potentially raises questions related to the students' attention i.e whether the students are following the lecture by applying the following texts, such as are you with me?, where were we at?, are you following me, listen to me, pay attention...etc.

The stage of Orientation refers to the moment when the lecturer gives outlines of lecture from the beginning to the end. Specifically, at this stage the lecturer details the objective to be achieved or tells the virtual class competences expected to be gained or developed by the students. In addition, lecturer also explains to the students indicators of the students' achievements. One more potential activity done by the lecture is explaining the assignments to be completed by the students. Further, at this stage the lecture may divide the students into groups through which the students are assigned some activities.

The stage of Presentation indicates the material given to the students in the virtual lecture. This is the core of the lecture and the stage is obligatory. The lecturer presents the material to the students. The ways of presenting the material varies. The first way of presentation is the lecturer's presentation where the lecturer himself or herself present the material. Obviously the presentation is made in one kind of text or genre, such as descriptin, explanation, report, exposition...etc. The second way of presentation is where the lecturer presentation is followed by another text. For example, in the lecture of English Language Skills after the lecturer presentation, the students are exposed to video watching where the students are asked to listen to a model in pronouncing segmental or suprasegmental aspects of English speech sounds. Thus, there are two texts now: the lecturer presentation and the video. This makes paratactic or compound texts. Another alternative way of presentation is where the lecturer presentation is followed by another person's text and inside the 'another person' text, another text is embedded. This is a case of 'paratactic and hypotactic' or 'compound and complex' texts. For example, the lecturer make the presentation of material about the use of vocabulary. The vocabulary presentation is followed by a manual worker's use of the vocabulary and inside the manual worker prsentation there is a nother story, which is about his experience related to the 
use of vocabulary. One of the indicators of Presentation stage is when the lecturer click the Share key in the lap top or coputer screen.

The stage of Group Work refers to the moment when the students in groups are involved in working together or discussing the best solution to a problem or issue exposed to them. One of the indicators used for this stage is the use of Breakthrough key on the lap top screen. Again this stage is optional. Once the students have been included in their groups the lecturer assign them to doing tasks, which is done in any kind of text (but mostly the text of procedure)

The stage of Discussion is one where the the lecturer asks the students to raise questions, stage suggestions, make offfer. The stage also emerges as the students initiate verbal and nonverbal acts. One of the indicators realizing this stage is using Raise Hand key on the lap top screen. Another way of initiating the student's act is by using the Chat button.

The stage of Consolidation refers to activities where skills in the use of language (listening, speaking, reading and writing) are developed through exercises or drills. This stage also involve exercises in the strucures or grammar and vocabulary as the mechanism of English language.

The stage of Evaluation refers to the lecturer's activities measuring the students' achivement in one session or topic of virtual lecture. One alternative of evaluating the students is by raising questions. Another way of doing evaluation is by asking the students to stage demonstration, simulation or role play activities.

In the stage of Reflection the students are asked to make a brief summary of the lecture, to ascertain aspects or parts of the lecture already and not yet mastered by the students and suggestions as to how the unmastered aspects to be learnt or studied.

The final stage of the schematic structure is Closure. This is the stage where the lecurer finalizes the virtul lecture. Firstly the lecture summarizes the lecture briefly. Then, the lecture highlights the main point. After that the lecture anticipate the future program. Lastly, the lecturer ends up the lecture.

Intensity of the Stage. The intensity of each stage of the schematic stuctures varies in terms of the time spent or duration. The time spent on each of the ten stages differs. The variation of time spent or duration is taken as the basis of intensity. Thus, the proportion of time spent at each stage indicates the intensity of the stage: the longer the time spent or duration, the more the intensity beomes. The intensity of each stage is indicated by the dimension of the (coloured) bar as summarized in the followng figure. As indicated in Figure 1, the stage of Presentation is the most in intensity or the dominant stage among the tens stages in the schematic structure. The least is the stage of Greeting. The Figure also shows comparisons of intensity of the ten stages. 


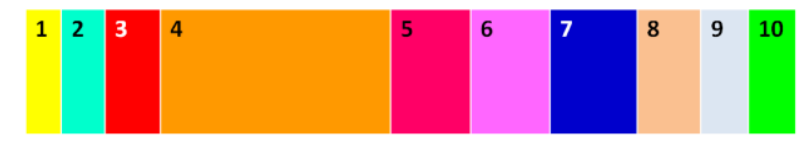

\author{
1. GREeting \\ 2. Class CheCKING \\ 3. ORIENTATION \\ 4. Presentation \\ 5. GROUP WORK \\ 6. DISCUSSION \\ 7. Consolidation \\ 8. EvaiduAtion \\ 9. REFLECTION \\ 10. Closure
}

Fig. 1. Intensity proportions of the schematic structures.

Linguistic Realizations. The Greeting stage is realized by expressions such as Good Morning, Good Afternoon, Hello. In addition to the greeting expressions, furher modification of statements may occur such as the following utterances Selamat pagi, waktu Medan 'Good morning, Medan time" This indicates that the lecture involves students who live or stay in other different zones from Medan. Some of the students live or stay in WITA (Central Indonesia) Zone Time whereas Medan belong to WIB (Western Indonesia) Zone Time.

The stage of Cecking Class begins with the lecturer's checking the students' presence by raising Question realized congruently or incongruently (i.e metaphorically) by expressions such as are you all in?, who has not appeared in the participant list?, where is P? (congruently) or I just want to make sure whether you are all in the participant list (metaphorically). The process is dominanty Relational ones. The students' understanding is cheked by by applying Question with Mental or Relational Process such as do you understand it? do you have any question, does it make sense?, is it understood? Further, the lecturer's checking students' awareness, attention or alertness is realized by Questions in Relational Process, such as are you with me?, where were we at?, are you following me. Alternatively, Command with Mental and Behavioural Process is used such please activate your camera, turn you video on, please click the Raise Hand sign on your (laptop, computer) screen. These latter expressions function as commands by listen to me, pay attention...etc do in the traditional or conventional classroom.

The Orientation stage begins with the lecturer outlining or elaborating the content of the lecture. Then, this is followed by the statement of the competence to be achieved with the indicator of the achivement, assignment to be completed and division of the students into groups. The content of the lecture and competence with its indicators are commonly realized by embedded clause with Relational Process, such as [[what we are going to talk about in this lecture]] is..., [[the competences that you are expected to achieve]] are..., the topic of our lecture today is..., our lecture will proceed in stages as..., the objectives in our lecture are..., the indicators for your achievement are.... The assignments of the students to tasks and dvision into groups are realized by modalized Material Proccess, such as you are required to do six kinds of assignment, you will have to do six kinds of assignment, you will be divided into groups, you have got to be in groups, etc.

The stage of Presentation gains intensity the most among the ten stages. This stage is linguistically realized by a (statement of) definition with Relational Process and Command in Imperative Mood with Material and Mental Process. There are three ways of staging 
Presentation. Firstly, the lecturer presentation is realized as phonetically, [p] is a voiceless bilabial plosive...look how I pronounce the sound... Secondly, the lecturer presentation followed by another text is realized as phonetically, $[p]$ is a voiceless bilabial plosivesound, nowwatch the video and listen carefully how the aspirated [p] sound is pronounced in English. Thirdly, the lecturer presentation followed by an instruction to watch video in which a strory on mispronuncing [p] is given by an Arabic speaker. The third way is linguistically realized as phonetically $[p]$ is a voceless bilabial plosive sound. Watch the video and listen to the ways how the sound $[p]$ is pronoumced.Then pay attentaion to the mispronunciation of the [p] sound by an Arabic speaker.

The stage of Group Work in the virtual lectures is linguistically realized by Command by the lecturer to perform an activity leading to grouping the students, such as please click the sign Beakthrough on your laptop and find your group members. By performing the activity the students are now divided into Group A, B, C, D, E each group with its members ranging from 4 to 6 students. This is then followed by the lecturer's inspection to each group in the virtual lecture. Following the inspection is the lecturer's giving assignment to each group (mostly) in procedure text, such as firstly read the problem, secondly discuss among you group member the best solution, thirdly write down your report and finally present your work in the discussion...etc.

The Discussion stage is realized by Command by the lecturer to perform an activity leading to returning to common room, such as please click the sign Return on your laptop and makefter that sure you are in the lobby or common room. After that expression a student as group representative is asked to present their result of their work. The presentation is realized in a kind of text (such as description, explanation, report, exposition, etc).

The stage of Discussion is done by the lecturer's presenting a problem or issue or,the lecturer's asking the student representative to present the results of their group works to be discussed by the whole participants in the virtual class. The linguistic realizations are respectively coded by Statement with embedded clause and metaphorica Command realized as the point (issue, problem) that I would like you to discuss is... could you please present the result of your group work to be discussed by other group members. After the presentation of the issue or problem, reaction is given by the students in any kind of text. Thus, there can be compounding of the text.

The stage of Consolidation is realized bytexts of Commands related to exercises and drills with the dominant Material Process by which the students are assigned to do some exercises or drills. The linguistic realizations are as follows: please do the following exercises..., you are required to complete the following dialogues,... please practise the conversation below... In addition to the exercises and drills, correct or key answers are provided. Another alternative of realizing the Consolidation stage is by assigning the students to multimedia exercises and drill with exact timing and automatic correct responses are given

Linguistic realizations coding the stage of Evaluation are the speech function of congruent and metaphorical Questions probing the students' higher order thinking skills such as what are the similarities and differences between $A$ and $B$ ?... if $A$ with its characteristics are raced with $B$, who will win the competition?...I wonder how would you solve the problem if you were in $B$ 's position. The questions are commonly in spoken text addressed to all the students and one answer is sampled out of the so many answers.

The stage of Reflection is realized by Statement where the students elaborate their mastery of the lecture. Linguistically the text begins with Statement with embedded clause and in Relational Process such as the part of the lecture [[that I have understood]] are ...This is then followed by the part of the lecture [[that I have not yet understood]] is...Then the stage 
is realized by the expression as follows in the future, I plan to apply X strategy to overcome problem.

The final stage of Closure is realized by a brief text summarizing all aspects covered in the lecture as what we have discussed in this lecture are $A, B, C$..the relation of the lecture to the future activity as next week we will be talking about $X, Y$ and $Z$ and finally the stage of Closure ends in a Statement with Relational Process as that's the end of our lecture and an expression of leave such as sorry, I leave now with the lecturer click the key Leave and the program disappears from the computer or android screen.

It is found that there are ten constituents or elements of the schematic structures of the virtual or on line lecture of English language, they are Greeting, Class Checking, Orientation, Presentation, Group Work, Discussion, Consolidation, Evaluation, Reflection, and Closure. The schematic structures are linear in the sense that the elements proceed linearly through stages. That is the reason for calling an element or constituent as a stage. Thus the elements are also called stages or structures.

With reference to their broad features the elements, constituents, stages or structures are either obligatory or optional. The obligatory elements are GREETING, PRESENTATION, DisCUSSION, CONSOLIDATION, EVALUATION REFLECTION and CLOSURE. The optional elements are CLASS CHECKING, ORIENTATION, and GROUP WORK. Specific or diacritic features may apply to a constituent or stage.

By its natures, a stage is potentially realized by a (kind of) text, copound text or compound and complex text. Firstly a stage or element of the schematic structure may be realized by a (kind of) text or genre. Secondly, a stage is potentially realized by a text followed by another one of the same or different kind, thus forming a compund text. Thirdly, a stage is realized by a text, which is folllowed by another of the same or different kind, in which another text has been embedded. This forms a compound and complex text as the realization of a stage.

The intensity of each stage of schematic structure varies in the sense that a stage differs from another with reference to the time spent or duration. The stage of Presentation is the most intense one among the ten stages and the stage of Greeting is the least.

One stage or element of schematic structure is realized by a specific linguistic features: experientially, logically, interpersonally, and textually. In addition, the stages may be realized by the digital verbal features such as the signs Share, Breakthrough, Chats, Participants, Raise Hand..etc as found in the lap top or computer screen. This confirms that there has been interaction of linguistic studies with ICT development.

The present study findings indicate that the schematic structures of the virtual English language lectures are constituently linear, varies in intensity with realizations ranging from salient linguistic features to compound and complex texts. Compared with previous study findings such as those by Flanders (1970), Sinclair and Coulthard (1975), Sinar (2002), Christies (2002), Kaur (2011), Alharbi (2016), and Hossein \&Pourchangi (2019) the present study indicates new findings in three respects. Firstly, stages of the schematic structures varies with reference to the time spent. The use of ICT equipment are explicitly time bound and this has impacts on the classroom management, which in effect is realized in the schematic structures of the virtual lectures. Secondly the realizations of schematic structures range from simple salient linguistic, i.e lexicogrammatical features through compound to compound-complex texts. Thirdly, the language of ICT equipments such as those found in the laptop, computer or android screens have interacted with the use of language as seen in linguistic study. The new findings of the present have both theoretical and practical implications. One pertinent theoretical implication is that the new findings justify the 
interrelatedness of context to context as theorized by [9] a great British linguist. This is in line with the interconnectedness of text and context in the sense that social context determines and is determined by social context by [11-13]. Practical implications of the present study finding is that the findings of the present study are worthwhile applying to developing and evaluating the effectiveness of and the achievements resulted from the virtual or on line lectures in English language learning. However, this study has limitation in the source of the data as this study is conducted to virtual lectures by the English Department of the Universitas Negeri Medan. Further studies with more sources of data and different research designs will indicate potential change or justification to the new findings.

\section{Conclusion}

The findings of the present study on English language lectures held at the English Department Faculty of Languages and Arts Universitas Negeri Medan indicate that the schematic structures of the virtual lectures are constituently linear, intensely varies and are realized by linguistic aspects ranging from simple lexicogrammatical to complex textual features. Three aspects are pertinent in the new findings of the present study, namely in the natures of the schematic structures, their realizations and interaction of the social context and text. The new findings have both theoretical implications and practical implications. It is suggested that the present study findings are applied in developing and evaluating virtual lectures and in assessing student achievements resulted from virtual lectures. It is also suggested that further studies should be done by other researchers by using more sources of data and different research designs.

\section{References}

[1] Hossein SM, Pourchangi AK. Schematic Structure of Literature Review in Research Articles: A Cross-Disciplinary Investigation. J of New Advances in Eng Lang Teaching and Appl Linguistics. 2019; 1(1):67-87.

[2] Alharbi S. Schematic Structure of Discussion of Result Sections in the Field of Dentistry: A Comparison of International and Local English-Medium Journals. Arab World English J (AWEJ). 2016; 8(2):61-76.

[3] Halliday, MAK. The Evolution of Language of Science. In Webster, J.J (ed.) Aspects of Language and Learning. Heidelberg: Springer; 2016. 26.

[4] Flanders NA. Analyzing Teaching Behavior. United States: Reading Mass., Addison Wesley Pub Co; 1970.

[5] Inecay G. The Role of Teacher Talk in the Young Learners' Language Proess. Procedia Social and Behavioral Sciences 2. Elsevier; 2010. p. 277-281.

[6] Kaur G. Study and analysis of Lecture model of teaching. Int J Edu Planning and Administration. 2011; 1(1):9-13.

[7] Sinar TS. Phasal and Experiential Realizations in Lecture Discourse: A Systemic-Functional Analysis, a dissertation at the Department of English Fakulti Bahasa dan Linguistik. Kuala Lumpur: Universiti Malaya; 2002.

[8] Christie F. Classroom Discourse Analysis: a functional perspectives. London: Continuum; 2002.

[9] Halliday MAK. The Notion of Context in Language Education. In Webster, J.J. (ed.) Language and Education. London: Continuum; 2007. 268-290.

[10] Halliday. An Itroduction to Functional Grammar. London: Routledge; 2014.

[11] Martin JR. English Text: System and Structure. Amsterdam: John Benjamins; 1992. 
[12] Martin JR, Rose D. Working with Discourse: Meaning Beyond the Clause. $2^{\text {nd }}$ Edition. London: Continuum; 2007.

[13] Martin JR, Rose D. Genre Relations: Mapping Culture. London: Equinox; 2008. 